\title{
USO DO MÉTODO DO SUBSTRATO CROMOGÊNICO PARA QUANTIFICAÇÃO DO NÚMERO MAIS PROVÁVEL DE BACTÉRIAS DO GRUPO COLIFORME EM ÁGUAS MINERAIS ENVASADAS *
}

\author{
DÉBORA LEAL COELHO ** \\ IDA CHAPAVAL PIMENTEL *** \\ MÁRCIA REGINA BEUX ****
}

\begin{abstract}
Avaliou-se a qualidade microbiológica da água mineral envasada e destinada ao mercado consumidor de Curitiba, quanto ao índice de contaminação por coliformes totais e fecais (Escherichia coli), através do uso do método do substrato cromogênico. Seis marcas, codificadas com as letras A, B , C, D, E e F, foram analisadas. Todas apresentaram ausência de coliformes fecais (Escherichia coli) e duas apresentaram presença de coliformes totais. As amostras foram consideradas próprias para consumo sob o ponto de vista microbiológico, pois no Brasil a legislação em vigor estabelece como padrão de potabilidade apenas a ausência de Escherichia coli, não fazendo referência a presença de outras bactérias do grupo coliforme. Os padrões de potabilidade especificados pelo CODEX ALIMENTARIUS e pela Comunidade Econômica Européia são mais rígidos, pois a presença de coliformes na água mineral pode indicar ausência de cuidados sanitários, problemas nas operações de captação, decantação, canalização, elevação mecânica, provisão em reservatórios, filtração, envasamento, carbonatação ou outros que possam alterar as propriedades características e a composição das mesmas. As amostras positivas foram submetidas a identificação bioquímica que revelou a presença de Enterobacter gergoviae e Citrobacter freundii, na amostra $A$ e de E. gergoviae e E. aerogenes na $\mathrm{B}$, microrganismos considerados coliformes totais, o que confirma o resultado obtido pelo método utilizado
\end{abstract}

\section{INTRODUÇÃO}

O consumo de água mineral envasada tornou-se popular somente na década de 80, em função da crescente preocupação da população com a saúde, decorrente da poluição progressiva das águas.

* Parte da Monografia apresentada à Coordenação do Curso de Ciências Biológicas como um dos requisitos para conclusão do Bacharelado em Ciências Biológicas da Universidade Federal do Paraná (UFPR) na área de Microbiologia - Estágio em Patologia Básica.

** Aluna do Curso de Ciências Biológicas, UFPR e estagiária do Laboratório de Microbiologia de Alimentos e Águas, Centro de Pesquisa e Processamento de Alimentos (CEPPA).

*** Engenheira Agrônoma, mestre, professora do Departamento de Patologia Básica, Setor de Ciências Biológicas, UFPR.

**** Bióloga, Mestre em Tecnologia de Alimentos, Coordenadora do Laboratório de Microbiologia de Alimentos e Águas, CEPPA. 
Segundo a Resolução n. 25/76 águas minerais são águas de origem profunda não sujeitas à influência de águas superficiais, provenientes de fontes naturais ou de fontes artificialmente captadas, que apresentam composição química ou propriedades físicas ou físico-químicas distintas das águas comuns.

Tradicionalmente, as águas minerais eram aquelas que emergiam naturalmente de fonte subterrânea sendo consumidas no lugar de origem. Atualmente são engarrafadas e vendidas em lugares distantes do seu sítio de origem. Existem também as águas minerais "artificiais" ou "manufaturadas" que são preparadas pela adição de minerais apropriados em água potável. Conseqüentemente tem sido necessário introduzir o termo água mineral "natural" para distinguir a água de nascentes subterrâneas de águas manufaturadas.

A água atua como substrato para bactérias, por isso é importante dispor de critérios ou padrões microbiológicos numericamente estabelecidos, considerando valores máximos aceitáveis de microrganismos, para não colocar em risco a saúde dos consumidores e garantir a potabilidade da água proveniente de fontes naturais ou artificialmente captadas e comercializadas envasadas. Estes critérios ou padrões são determinados pela legislação e variam de acordo com a origem da água analisada (fonte, rio, lago, rede pública, mineral).

Segundo a legislação brasileira (Resolução n. 25/76) as águas minerais devem estar isentas apenas de Escherichia coli para que sejam consideradas potáveis sob o ponto de vista bacteriológico, apesar da potabilidade poder ser também verificada através de análises indicadoras de contaminação, como a contagem de bactérias heterotróficas, coliformes totais ou coliformes fecais.

Águas minerais naturais não são estéreis, apresentando microrganismos que lhe são próprios, isto é, existentes antes de qualquer tratamento ou processamento. Embora, estes microrganismos conhecidos como autóctones permaneçam num nível baixo em termos populacionais enquanto a água está em seu ambiente natural, logo após o engarrafamento começam a crescer rapidamente. Juntamente com as bactérias autóctones desenvolvem-se as indígenas e o melhor crescimento destas tem sido observado em águas com alto conteúdo mineral, sendo que desenvolvem-se melhor em temperaturas próximas a $20^{\circ} \mathrm{C}$. Acreditase que maior número de microrganismos são encontrados em águas de garrafas plásticas, devido à característica do plástico de permitir a passagem de $\mathrm{O}_{2}$, proporcionando superfície de crescimento adequada para as bactérias. 
Para a Saúde Pública, o significado das bactérias indígenas tem sido discutido. Alguns autores têm indicado que estas bactérias são incapazes de colonizar o trato digestivo, possivelmente devido à sua inabilidade em sobreviver em potencial redox baixo e a temperatura de $37{ }^{\circ} \mathrm{C}$ deste ambiente. Conseqüentemente, estas bactérias são consideradas sem perigo à saúde pública. Entretanto, algum interesse tem sido expressado sobre a habilidade destas bactérias em converter o nitrato das águas minerais em nitrito (VIEIRA, 1989).

Outro tipo de flora bacteriana que pode surgir na água mineral, mas não proveniente da fonte são as chamadas bactérias alóctones, que aparecem durante as etapas prévias ao engarrafamento, durante o processamento ou mesmo do ambiente.

O crescimento significativo destas bactérias é raro, principalmente devido a seus requerimentos nutricionais. Os tipos mais persistentes de bactérias alóctones apresentam características fisiológicas semelhantes às espécies autóctones. Estas incluem espécies mesófilas gram negativas, tais como: Pseudomonas cepacia, Pseudomonas multivorans, Pseudomonas fluorescens e Pseudomonas aeruginosa (VIEIRA, 1989).

As espécies patogênicas de interesse primário em águas minerais são: Salmonella typhi, Salmonella paratyphi, Vibrio cholerae, Shigella sp, Pseudomonas cepacia, vírus entéricos e alguns protozoários. Estes organismos chegam até a água por contaminação fecal ou outras vias, seja diretamente na fonte ou durante o engarrafamento. As características de crescimento e sobrevivência destes organismos nas águas minerais requerem mais estudos.

Para enumeração das bactérias do grupo coliforme são preconizados três métodos segundo o Standard methods of the examination of water and wastewater (APHA, 1995). Destes métodos, dois quantificam os coliformes através do uso de tubos múltiplos e revelam a densidade bacteriana através do número mais provável (NMP); o padrão e o substrato cromogênico. O terceiro, conhecido como o da membrana filtrante, permite visualização do número de colônias de microrganismos existentes, expressando o resultado em unidades formadoras de colônias (UFC).

O uso do método do substrato cromogênico permite determinar simultaneamente os coliformes totais e Escherichia coli presentes em uma determinada amostra.

O método do substrato cromogênico define como coliformes totais bactérias na forma de bastonetes, gram negativas, não formadoras de esporos, aeróbias ou anaeróbias facultativas, que hidrolizam o substrato Orto-nitrofenil- $\beta$-D-galactopiranosídeo (ONPG), transformando-o em Ortonitrofenol. O grupo inclui cerca de 20 espécies, dentre as quais encontram- 
se tanto bactérias originárias do trato gastrintestinal de humanos e outros animais de sangue quente, como também diversos gêneros e espécies de bactérias não entéricas, como Serratia e Aeromonas, por exemplo. Por esta razão, sua enumeração em água e alimentos é menos representativa como indicação de contaminação por fezes, do que a enumeração de coliformes fecais ou Escherichia coli (SILVA \& JUNQUEIRA, 1995). O método reconhece como coliformes totais as cavidades com bactérias que alteram a coloração do meio, de incolor para amarelo.

O resultado para Escherichia coli é positivo quando as cavidades positivas apresentam além da coloração amarela, fluorescência azul sob luz ultravioleta (360 nm), devido à ação do 4-metilumbeliferil- $\beta$-D-glucoronídeo (MUG) utilizado como substrato para indicar a presença da enzima bglucoronidase. Esta enzima é caracteristicamente produzida pela Escherichia coli e quando o MUG é degradado pela b-glucoronidase o produto resultante 4-metilumbeliferona é fluorescente sob luz ultravioleta.

O grupo dos coliformes fecais inclui pelo menos três gêneros, Escherichia, Enterobacter e Klebsiella, dos quais dois (Enterobacter e Klebsiella) incluem cepas de origem não fecal. Por este motivo, a presença de coliformes fecais em alimentos é menos representativa, como indicação de contaminação fecal, do que a enumeração direta de Escherichia coli, porém, muito mais significativa do que a presença de coliformes totais, dada a alta incidência de Escherichia coli dentro do grupo fecal.

Utilizando-se do método substrato cromogênico (mais recente), o presente trabalho analisou seis marcas de água mineral de um litro, envasadas e disponíveis no mercado de Curitiba, tendo como objetivo avaliar o índice de contaminação por coliformes totais e Escherichia coli, identificando as espécies recuperadas a partir das cavidades positivas para coliformes totais.

\section{MATERIAL E MÉTODOS}

Foram analisadas seis amostras de água mineral envasadas em garrafas plásticas de um litro, compradas no mercado da cidade de Curitiba, em duplicata, utilizando-se o método de contagem de coliformes totais e Escherichia coli através do uso de substrato cromogênico, preconizado pelo Standard methods of the examination of water and wastewater, (APHA, 1995).

Para quantificação dos coliformes totais e Escherichia coli foi utilizado o sistema Quanti-Tray, que é composto por frascos estéreis graduados com capacidade para $100 \mathrm{~mL}$, flaconetes com meio de cultura, cartelas estéreis com 97 cavidades e seladora Quanti-Tray, marca IDEXX. 
O processo foi desenvolvido dentro de capela de fluxo laminar, sendo cada amostra, após assepsia do frasco com algodão embebido em álcool, transferida para um frasco estéril graduado. Em seguida adicionou-se para cada frasco um flaconete contendo a quantidade exata de meio de cultura contido no flaconete. Após dissolução do meio de cultura transferiu-se a amostra para uma cartela plástica estéril e, posteriormente, para a seladora. Esta apresenta suporte de borracha no qual as cartelas se encaixam. Após seladas as cartelas foram incubadas em estufa bacteriológica regulada a $35 \pm 05^{\circ} \mathrm{C}$ por 24 horas.

No sistema utilizado, o Quanti - Tray, os tubos múltiplos são substituídos por 97 cavidades contidas na cartela plástica estéril. O resultado de coliformes totais e Escherichia coli é obtido simultaneamente. Este método amplia, em comparação ao método padrão de fermentação em tubos múltiplos, o número de combinações positivas possíveis, fornecendo resultados mais precisos.

Os resultados são expressos através do NMP/100 mL da amostra obtido na Tabela de combinação de cavidades positivas.

Após a leitura, com o intuito de identificar os microrganismos, o meio de cultura contido nas cavidades das cartelas que apresentaram resultado positivo foi transferido, com auxílio de alça descartável, para tubos contendo caldo verde brilhante lactose bile a $2 \%$ suplementado com MUG. Este é um caldo seletivo para coliformes totais que também permite verificar o crescimento de Escherichia coli (10 g peptona, $10 \mathrm{~g}$ lactose, $20 \mathrm{~g}$ bile de boi desidratada, 0,0133 g verde brilhante, $1000 \mathrm{~mL}$ água destilada e $0,1 \mathrm{~g}$ de MUG) e para placas de ágar eosina azul de metileno - ágar EMB, seletivo para bactérias gram negativas (10 g peptona, $10 \mathrm{~g}$ lactose, $2,0 \mathrm{~g}$ hidrogenofosfato de potássio, 0,4 g eosina amarela, 0,065 g azul de metileno, $15,0 \mathrm{~g}$ ágar, $1000 \mathrm{~mL}$ água destilada). Tanto os tubos quanto as placas foram incubados em estufa bacteriológica regulada a $35 \pm 0,5{ }^{\circ} \mathrm{C}$ por 24 horas. Nos tubos contendo verde brilhante foi observada a presença ou não de turvação e formação de gás, além de fluorescência sob luz ultravioleta. As colônias que cresceram nas placas de EMB foram repicadas para o ágar tríplice açúcar e ferro - TSI (15 g peptona, $5 \mathrm{~g}$ proteosepeptona, 3,0 g extrato de carne, 3,0 g extrato de levedura, 5,0 $\mathrm{g}$ cloreto de sódio, $10 \mathrm{~g}$ lactose, $10 \mathrm{~g}$ sacarose, 1,0 glicose, 0,2 $\mathrm{g}$ sulfato ferroso amônia $6 \mathrm{H}_{2} \mathrm{O}, 0,2 \mathrm{~g}$ tiossulfato de sódio, $0,024 \mathrm{~g}$ vermelho de fenol, $13 \mathrm{~g}$ ágar, $1000 \mathrm{~mL}$ água destilada) e para o ágar lisina-ferro-LIA (5,0 g peptona de carne, 3,0 g extrato de levedura, 1,0 g glicose, $10 \mathrm{~g}$ I-lisina monocloridrato, $0,04 \mathrm{~g}$ tiossulfato de sódio, $0,5 \mathrm{~g}$ citrato férrico amoniacal, $0,02 \mathrm{~g}$ púrpura de bromocresol, $15 \mathrm{~g}$ ágar, $1000 \mathrm{~mL}$ água destilada), que serviram para isolamento das colônias. 
Para identificação das colônias, repicadas do EMB para os meios TSI e LIA, foi utilizado mini kit de provas bioquímicas para enterobactérias que é composto pelas seguintes provas: desaminação do $L$ triptofano, descarboxilação da lisina, descarboxilação da ornitina e indol, leitura de citrato e fermentação da rhamnose. O mini-kit não apresenta prova de fermentação da lactose, por isso deve ser complementado.

\section{RESULTADOS E DISCUSSÃO}

As marcas que apresentaram coloração amarelo foram a $\mathbf{A}$ e a $\mathbf{B}$, sendo que ambas apresentaram 2 cavidades positivas, indicando a presença de coliformes totais. No entanto estas cavidades não apresentaram fluorescência azul sob luz ultravioleta, o que indica ausência de Escherichia coli nas amostras. Com o número de cavidades positivas obteve-se o número mais provável de coliformes totais de acordo com a Tabela apropriada. O resultado encontrado de coliformes totais foi de 2,0 NMP/100 para as amostras A e B e ausência de Escherichia coli em 100 $\mathrm{mL}$, para todas as amostras (Tabela 1 ).

\section{TABELA 1 - NÚMERO MAIS PROVÁVEL DE COLIFORMES TOTAIS E Escherichia coli EM $100 \mathrm{~mL}$ DE AMOSTRA PARA AS SEIS MARCAS ANALISADAS}

\begin{tabular}{cccc}
\hline \multicolumn{4}{c}{ NMP/100 $\mathbf{~ m L}$} \\
\hline Marca & $\begin{array}{c}\text { Coliformes } \\
\text { Totais }\end{array}$ & $\begin{array}{c}\text { Coliformes } \\
\text { Fecais }\end{array}$ & $\begin{array}{c}\text { Limite de } \\
\text { Confiança }\end{array}$ \\
\hline A & 2,0 & Ausência & $0,69 \rightarrow 8,90$ \\
B & 2,0 & Ausência & $0,26 \rightarrow 7,10$ \\
C & Ausência & Ausência & - \\
D & Ausência & Ausência & - \\
E & Ausência & Ausência & - \\
F & Ausência & Ausência & - \\
\hline
\end{tabular}

Segundo a legislação vigente no Brasil (Resolução n. 25/76) estas amostras seriam aprovadas, pois a única especificação é a ausência de Escherichia coli em $100 \mathrm{~mL}$ da amostra. Contudo existem outras especificações propostas para águas minerais naturais engarrafadas. As especificações do CODEX ALIMENTARIUS (1995) incluem como primeiro exame coliformes fecais (Escherichia coli), Estreptococos-D (enterococos) e Pseudomonas aeruginosa (Tabela 2). O segundo exame, envolvendo as mesmas análises, será necessário caso o número de enterococos seja maior ou igual a um ou menor ou igual a dois. O Codex não inclui critérios para contagem total em placas de aeróbios, reconhecendo o fato de que 
águas minerais naturais engarrafadas apresentam microbiota indígena inofensiva, que chegam a populações tão altas quanto $10^{6} \mathrm{cél} / \mathrm{mL}$ durante a comercialização. Entretanto, o código inclui especificações para a contagem total de aeróbios da água, na nascente, o que depende do conhecimento da ecologia microbiana de cada fonte de água em particular.

\section{TABELA 2 - ESPECIFICAÇÕES MICROBIOLÓGICAS PROPOSTAS PARA ENGARRAFAMENTO DE ÁGUAS MINERAIS NATURAIS NÃO CARBONATADAS (CODEX ALIMENTARIUS, 1995)}

\begin{tabular}{|c|c|c|c|c|}
\hline \multicolumn{5}{|l|}{$1^{\circ}$ EXAME } \\
\hline Organismo/grupo & Amostra & \multicolumn{3}{|c|}{ Decisão } \\
\hline Coliformes & $1 \times 250 \mathrm{~mL}$ & \multicolumn{3}{|c|}{ aceito se ausente } \\
\hline Estreptococos-D & $1 \times 250 \mathrm{~mL}$ & \multicolumn{3}{|c|}{ se $\geq 1$ ou $\leq 2$ - fazer $2^{\circ}$ exame } \\
\hline \multicolumn{5}{|l|}{ (enterococos) } \\
\hline Pseudomonas aeruginosa & $1 \times 250 \mathrm{~mL}$ & \multicolumn{3}{|c|}{ aceito se ausente / rejeitado se $\geq 1$} \\
\hline \multicolumn{5}{|l|}{$2^{\circ}$ EXAME } \\
\hline Organismo/grupo & $\mathbf{N}$ & $\mathbf{C}$ & $\mathbf{m}$ & $\overline{\mathbf{M}}$ \\
\hline Coliformes & $4 \times 250 \mathrm{~mL}$ & 1 & 0 & 2 \\
\hline Estreptococos-D & $4 \times 250 \mathrm{~mL}$ & 1 & 0 & 2 \\
\hline \multicolumn{5}{|l|}{ (enterococos) } \\
\hline Pseudomonas aeruginosa & $4 \times 250 \mathrm{~mL}$ & 0 & 0 & 0 \\
\hline
\end{tabular}

$\mathrm{N}=$ número de amostras submetidas a exame.

$\mathrm{C}=$ número de unidades defeituosas tolerado entre as unidades de amostras coletadas.

$\mathrm{m}=$ valor de contagem mínima.

$\mathrm{M}=$ valor de contagem máxima

$\mathrm{Na}$ Tabela 3 pode-se verificar as especificações propostas pela Comunidade Econômica Européia (80/777/EEC), que inclui contagem total de colônias, ausência de parasitas e microrganismos patogênicos como: Escherichia coli, coliformes, Enterococcus faecalis, anaeróbios sulfito redutores esporulados e Pseudomonas aeruginosa (VIEIRA, 1989). 


\section{TABELA 3 - ESPECIFICAÇÕES PROPOSTAS PELA COMUNIDADE ECONÔMICA EUROPÉIA (80/777/EEC) PARA ÁGUAS MINERAIS NATURAIS ENVASADAS}

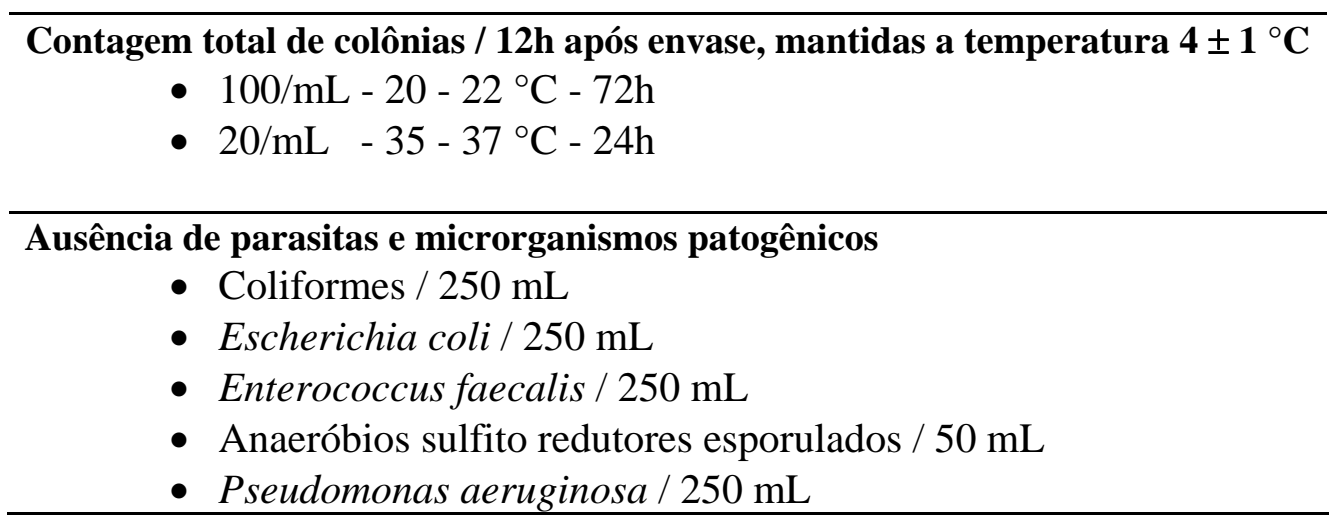

Na Tabela 4 estão demonstradas as propostas da Legislação Espanhola pelo real decreto 2119/81, no qual as análises são divididas conforme o local de coleta (VIEIRA, 1989).

\section{TABELA 4 - ESPECIFICAÇÕES PROPOSTAS PELA LEGISLAÇÃO ESPANHOLA (REAL DECRETO 2119/81) PARA AS ÁGUAS MINERAIS NATURAIS ENVASADAS}

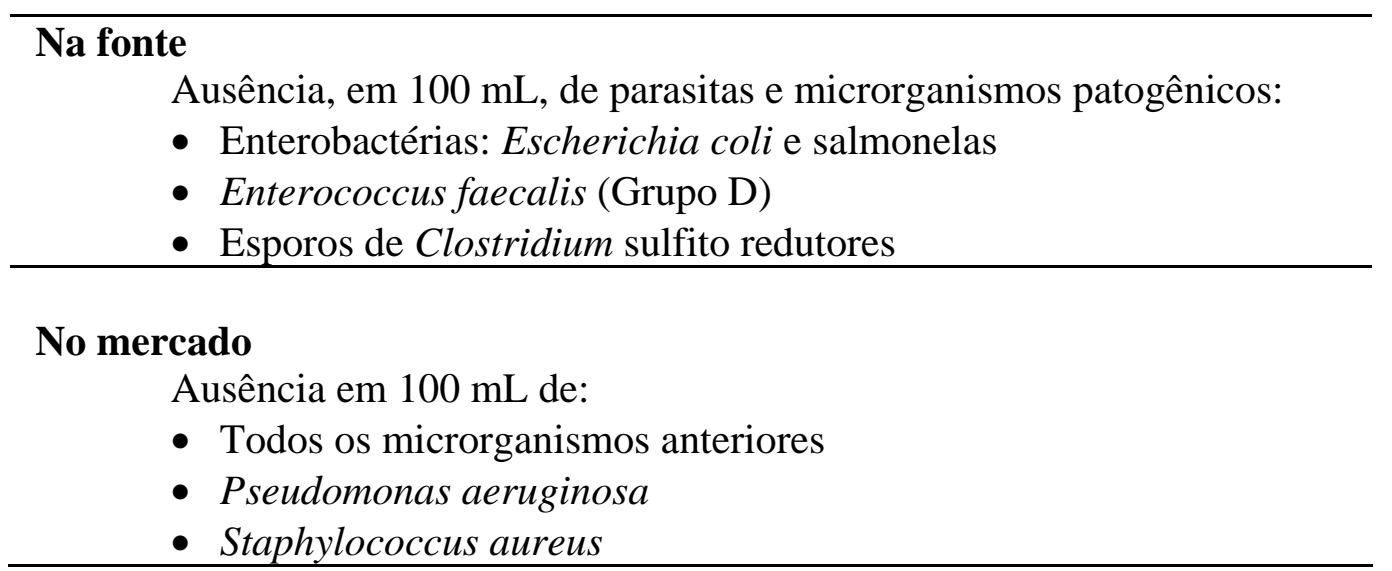

Para reiterar o resultado obtido pelo método do substrato cromogênico, todos os tubos contendo verde brilhante lactose bile a $2 \%$ com MUG apresentaram turvação e formação de gás, não revelando a presença de fluorescência, mas confirmando a presença de coliformes totais e a ausência de Escherichia coli. 
As quatro placas de Ágar Eosina Azul de Metileno (EMB) apresentaram crescimento, confirmando a presença de bacilos Gram negativos.

As enterobactérias identificadas nas amostras A e B estão descritas na Tabela 5 .

\section{TABELA 5 - TABELA DE IDENTIFICAÇÃO DOS MICRORGANISMOS ISOLADOS DAS QUATRO CAVIDADES POSITIVAS PARA COLIFORMES TOTAIS}

\begin{tabular}{c|c|c|c|c|c|c|c|c|c|c|c|c|l}
\hline $\begin{array}{c}\text { Amostra } \\
\mathrm{n}^{\circ}\end{array}$ & Cav & Phe & Lac & $\mathrm{H}_{2} \mathrm{~S}$ & Glu & Gás & Lis & I & Crn & Mot & KK & Rha & Identificação \\
\hline $\mathrm{A}$ & 1 & - & + & + & + & + & - & - & - & + & - & + & $\begin{array}{l}\text { Citrobacter } \\
\text { freundii }\end{array}$ \\
\hline $\mathrm{A}$ & 2 & - & - & - & + & + & + & - & + & + & + & + & $\begin{array}{l}\text { Enterobacter } \\
\text { gergoviae }\end{array}$ \\
\hline $\mathrm{B}$ & 1 & - & - & - & + & + & + & - & + & + & + & + & $\begin{array}{l}\text { Enterobacter } \\
\text { gergoviae }\end{array}$ \\
\hline $\mathrm{B}$ & 2 & - & + & - & + & - & + & - & + & + & + & + & $\begin{array}{l}\text { Enterobacter } \\
\text { aerogenes }\end{array}$ \\
\hline
\end{tabular}

Os microrganismos isolados das cavidades contidas nas cartelas de quantificação confirmam a presença de coliformes totais nas amostras A e $\mathrm{B}$ analisadas.

\section{CONCLUSÃO}

As seis marcas de água mineral testadas atendem aos parâmetros estabelecidos pela legislação, apesar de duas marcas apresentarem presença de coliformes totais.

Os microrganismos identificados a partir das amostras positivas pertencem as espécies Enterobacter gergoviae, Enterobacter aerogenes e Citrobacter freundii, comprovando que o método do substrato cromogênico utilizado recuperou os coliformes presentes nas amostras.

\section{Abstract}

Microbiological quality of the bottled mineral water consumed in Curitiba, Paraná State, Brazil, was evaluated for total and fecal coliforms (Escherichia coli) throughout the method of chromogenic substrate. Six brands, codified with the letters A, B, C, D, E, and F, were analyzed. All brands presented no fecal coliforms while two samples showed presence of total coliforms. The samples were considered suitable for consumption under microbiological means. In Brazil, the current 
legislation only establishes as potability standard the absence of Escherichia coli, not referring to the presence of any other bacteria of the coliform group. The standards of potability specified by CODEX ALIMENTARIUS and the European Economic Community are more tight, considering the presence of coliforms in the mineral water as an indicative of inefficient sanitary cares and problems in the process operations and others that may modify the characteristic properties and their composition. The positive samples were submitted to the biochemical identification showing up the presence of Enterobacter gergoviae and Citrobacter freundi, in the sample $A$ and of $E$. gergoviae and $E$. aerogenes in the sample $\mathrm{B}$, considered total coliform microorganisms, confirming the previous result reached with the applied method.

\section{REFERÊNCIAS BIBLIOGRÁFICAS}

1 BRASIL. Ministério da Saúde. Resolução n. 25, de 1976. Estabelece padrões de identidade e qualidade para águas minerais e água natural de fonte. Diário Oficial [da República Federativa do Brasil], de 16 de março de 1977.

2 APHA. Standard methods for the examination of water and wastewater: part 9000: microbiological examination. 19. ed. Washington, 1995. p. 9-51.

3 CODEX ALIMENTARIUS. Azúcares, productos del cacao y el chocolate y productos varios. Roma, Itália : FAO/OMS, [1995]. v.11.

4 SILVA, N. da, JUNQUEIRA, V.C.A. Métodos de análise microbiológica de alimentos. Campinas, 1995. 229 p. (Manual Técnico, 14).

5 VIEIRA, M. B. C. M. Água mineral: aspectos microbiológicos e a legislação vigente. In: ENCONTRO NACIONAL DE ANALISTAS DE ALIMENTOS, 4., Belo Horizonte, 03-07 de outubro de 1988. Anais... Belo Horizonte : Lemi, 1989. p. 125-130. 